\title{
Nurse-led case management for ambulatory complex patients in general health care: A systematic review
}

\author{
Corine H.M. Latour ${ }^{\mathrm{a}}$, Daniëlle A.W.M. van der Windt ${ }^{\mathrm{b}, *}$, Peter de Jonge ${ }^{\mathrm{c}}$, Ingrid I. Riphagen ${ }^{\mathrm{d}}$, \\ Rien de $\operatorname{Vos}^{\mathrm{e}}$, Frits J. Huyse ${ }^{\mathrm{f}}$, Wim A.B. Stalman ${ }^{\mathrm{b}}$ \\ ${ }^{a}$ Psychiatric Consultation and Liaison Service, VU University Medical Center, Amsterdam, The Netherlands \\ ${ }^{\mathrm{b}}$ EMGO Institute and Department of General Practice, VU University Medical Center, Amsterdam. The Netherlands \\ ${ }^{\mathrm{c} D e p a r t m e n t ~ o f ~ P s y c h i a t r y, ~ U n i v e r s i t y ~ M e d i c a l ~ C e n t e r ~ G r o n i n g e n, ~ G r o n i n g e n, ~ T h e ~ N e t h e r l a n d s ~}$ \\ ${ }^{\mathrm{d}}$ Medical Library, Vrije Universiteit, Amsterdam, The Netherlands \\ ${ }^{\mathrm{e}}$ Amsterdam School of Nursing, Academic Medical Center, Amsterdam, The Netherlands \\ ${ }_{\mathrm{f}}^{\mathrm{f}}$ Department of Internal Medicine, University Medical Center Groningen, Groningen, The Netherlands
}

Received 23 March 2006; received in revised form 9 August 2006; accepted 17 October 2006

\begin{abstract}
Objective: The aim of this study was to summarize the available literature on the effectiveness of ambulatory nurse-led case management for complex patients in general health care. Method: We searched MEDLINE, EMBASE, the Cochrane Controlled Trials Register, and Cinahl. We included randomized controlled trials, controlled clinical trials, controlled before/after study, and time series studies; identified references were screened by two reviewers. Two reviewers rated the quality of each article. Data extracted from the selected publications included design, characteristics of the participants, the intervention, type of outcome
\end{abstract}

measures, and results. Results: We identified 10 relevant publications. Nine studies used readmission rate as primary outcome. Fewer studies investigated duration of hospital readmissions, emergency department (ED) visits, functional status, quality of life, or patient satisfaction. In general, results with regard to the effectiveness of case management were conflicting. Conclusion: There is moderate evidence that case management has a positive effect on patient satisfaction and no effect on ED visits. It was not possible to draw firm conclusions on the other outcomes.

(C) 2007 Elsevier Inc. All rights reserved.

\section{Introduction}

Case management has, in recent years, been described as a solution to improve outcomes in complex patients [1-3]. Case management is concerned with an optimisation of multidisciplinary treatment for complex patients and on the integral care needs of the individual patient without focusing on only one specific illness or population (as in disease management [4]). Case management has been applied in the

Abbreviations: RCT, randomized clinical trial; CCT, controlled clinical trials; CBA, controlled before/after study; ED, emergency department.

* Corresponding author. EMGO Institute and Department of General Practice, VU University Medical Center, Van der Boechorststraat 7, 1081 BT Amsterdam, The Netherlands.

E-mail address: dawm.vanderwindt@vumc.nl (D.A.W.M. van der Windt). field of psychiatry for a long time. A review of the literature [6] showed that psychiatric case management in psychiatric health care may be associated with improved compliance and reductions in hospitalization. Over the past decade, more attention has been directed toward the effects of case management in general health care [2,7-10].

With respect to the characteristics of complex patients in general health care, these patients have by definition multiple health problems in various health domains. In other words, case management is about flexible treatment plans in mixed populations. We defined complex patients as patients with acute or chronic multimorbid medical condition(s) or symptoms with psychiatric comorbidity [11] and/or social vulnerabilities, with more than one health care worker involved in the care process. These complex conditions have 
a deleterious effect on health care utilization, quality of life, morbidity, compliance, and mortality in primary care as well as in hospital care [5,12-14], leading to an extended duration of hospital stay, more doctor visits and emergency department (ED) visits, and more readmissions [15-17]. Because of an increase in the number of patients with complex problems due to an ageing population, increasing comorbidity, and a more complex health care organisation [20,21], it is expected that more patients will need case management in the years to come $[3,7,18,19]$. We aimed to summarize evidence for the effectiveness of postdischarge nurse-led case management for complex patients by means of a systematic review.

\section{Methods}

\section{Criteria for inclusion of studies in this review}

\section{Types of studies}

Studies published from 1966 until June 15, 2005, were eligible for inclusion in the review; no language restrictions were applied. We included randomized controlled trials (RCTs), controlled clinical trials (CCTs), controlled before/ after studies (CBAs), and time series studies addressing the effectiveness of postdischarge nurse-led case management for complex patients in general health care.

\section{Types of participants}

Studies considered for inclusion in this review focused on ambulatory patients over 18 years of age and were defined as complex; patients with acute or chronic medical condition(s) and described other vulnerabilities, such as (psychiatric) comorbidity; frail elderly people; and patients with social problems, reduced functional status, or poor quality of life, and with more than one health care worker involved in the care process.

Studies were excluded if they focused on only one specific disease, with less attention paid to other vulnerabilities or comorbidities (e.g., disease management protocols) or when the case management focused solely on psychiatric/mental health care.

\section{Types of interventions}

Interventions had to be implemented in an ambulatory setting. The criteria used to identify case management were assessment of the client's needs, development of a comprehensive service plan, arrangement of service delivery, monitoring and assessment of services, evaluation, and follow-up [6]. There were no limits with regard to the types of intervention.

We excluded studies in which the care was only guided by chronic disease management protocols or guidelines, or

\begin{tabular}{|c|c|c|c|c|}
\hline \multicolumn{2}{|l|}{ Potential relevant studies } & \multicolumn{3}{|c|}{ Excluded: 1533} \\
\hline $\begin{array}{l}\text { 1.Medline: } \\
\text { 2..Embase: } \\
\text { 3.Cochrane: }\end{array}$ & $\begin{array}{r}928 \\
195 \\
79\end{array}$ & \multirow[b]{8}{*}{ Excluded: } & & $\nabla$ \\
\hline 4.Cinahl: & 416 & & \multirow{18}{*}{$\begin{array}{l}\text { Medline: } \\
\text { design:16 } \\
\text { population: } 34 \\
\text { intervention: } 6 \\
\text { outcomes: } 1 \\
\text { Embase: } \\
\text { design: } 0 \\
\text { population: } 6 \\
\text { intervention: } 5 \\
\text { outcomes:0 } \\
\text { Cochrane } \\
\text { design: } 0 \\
\text { population: } 3 \\
\text { intervention:0 } \\
\text { outcomes: } 0 \\
\text { Cinahl: } \\
\text { design: } 10 \\
\text { population: } 8 \\
\text { intervention: } 3 \\
\text { outcomes: } 0 \\
\text { Reference } \\
\text { checking: } \\
\text { design: } 0 \\
\text { population: } 2 \\
\text { intervention: } 1 \\
\text { outcomes: } 0\end{array}$} & \multirow{18}{*}{$\begin{array}{l}\text { Medline: } \\
\text { design: } 656 \\
\text { population: } 75 \\
\text { intervention: } 98 \\
\text { outcomes: } 35 \\
\text { Embase: } \\
\text { design: } 124 \\
\text { population: } 30 \\
\text { intervention: } 23 \\
\text { outcomes:6 } \\
\text { Cochrane } \\
\text { design: } 8 \\
\text { population: } 41 \\
\text { intervention: } 15 \\
\text { outcomes: } 11 \\
\text { Cinahl: } \\
\text { design: } 297 \\
\text { population: } 65 \\
\text { intervention: } 22 \\
\text { outcomes: } 11 \\
\text { Reference } \\
\text { checking: } \\
\text { design: } 5 \\
\text { population: } 5 \\
\text { intervention: } 5 \\
\text { outcomes: } 1\end{array}$} \\
\hline 5.Reference checking & 20 & & & \\
\hline total: & 1638 & & & \\
\hline & & & & \\
\hline \multirow{5}{*}{\multicolumn{2}{|c|}{$\begin{array}{lr}\text { Full text } & \\
\text { 1.Medline: } & 64 \\
\text { 2. Embase: } & 12 \\
\text { 3. Cochrane: } & 4 \\
\text { 4. Cinahl: } & 21 \\
\text { 5. Reference checking: } & 4 \\
\end{array}$}} & & & \\
\hline & & & & \\
\hline & & & & \\
\hline & & & & \\
\hline & & & & \\
\hline Total : & 105 & & & \\
\hline 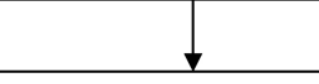 & & & & \\
\hline Included in the study: & & & & \\
\hline 1. Medline: & 7 & & & \\
\hline 2. Embase: & 1 & & & \\
\hline 3 Cochrane.: & 1 & & & \\
\hline 4. Cinahl: & 0 & & & \\
\hline 5.Reference checking: & 1 & & & \\
\hline Total: & 10 & & & \\
\hline
\end{tabular}

Fig. 1. Process of study selection. 
Table 1

Results of quality assessment of the included studies

\begin{tabular}{|c|c|c|c|c|c|c|c|}
\hline Authors & $\begin{array}{l}\text { Concealment } \\
\text { of allocation }\end{array}$ & $\begin{array}{l}\text { Baseline } \\
\text { comparability }\end{array}$ & $\begin{array}{l}\text { Blinded assessment } \\
\text { of outcomes }\end{array}$ & & $\begin{array}{l}\text { Follow-up, } \\
\text { patients }\end{array}$ & $\begin{array}{l}\text { Follow-up, } \\
\text { professionals }\end{array}$ & $\begin{array}{l}\text { Protection against } \\
\text { contamination }\end{array}$ \\
\hline \multirow[t]{3}{*}{ Brand et al. [24] } & + & - & Readmission & + & + & $\mathrm{X}$ & $?$ \\
\hline & & & ED visits & + & + & & \\
\hline & & & Quality of life & - & - & & \\
\hline \multirow[t]{3}{*}{ Laramee et al. [1] } & $?$ & - & Readmission & + & + & $\mathrm{X}$ & + \\
\hline & & & Hospital days & + & + & & \\
\hline & & & Patient satisfaction & - & + & & \\
\hline \multirow[t]{3}{*}{ Lob et al. [25] } & $?$ & $?$ & Readmission & + & - & $\mathrm{X}$ & + \\
\hline & & & Hospital days & + & - & & \\
\hline & & & ED visits & + & - & & \\
\hline McCorckle et al. [18] & + & - & Functional status & $?$ & + & $\mathrm{X}$ & + \\
\hline \multirow[t]{5}{*}{ Naylor et al. [2] } & + & + & Readmission & + & + & $\mathrm{X}$ & + \\
\hline & & & Hospital days & + & + & & \\
\hline & & & ED visits & + & + & & \\
\hline & & & Functional status & + & - & & \\
\hline & & & Patient satisfaction & + & - & & \\
\hline \multirow[t]{2}{*}{ Rich et al. [19] } & $?$ & + & Readmission & + & + & $\mathrm{X}$ & + \\
\hline & & & Hospital days & + & + & & \\
\hline \multirow[t]{3}{*}{ Rich et al. [3] } & + & + & Readmission & + & + & $\mathrm{X}$ & + \\
\hline & & & Hospital days & + & + & & \\
\hline & & & Quality of life & $?$ & - & & \\
\hline \multirow[t]{3}{*}{ Sommers et al. [7] } & + & - & Readmission & + & + & + & + \\
\hline & & & ED visits & + & + & & \\
\hline & & & Quality of life & - & - & & \\
\hline \multirow[t]{4}{*}{ Weinberger et al. [9] } & + & + & Readmission & + & + & $\mathrm{X}$ & + \\
\hline & & & Hospital days & + & + & & \\
\hline & & & Quality of life & + & + & & \\
\hline & & & Patient satisfaction & + & + & & \\
\hline Williams et al. [26] & + & $?$ & Readmission & $?$ & $?$ & $\mathrm{X}$ & + \\
\hline
\end{tabular}

(+) Positive; (-) negative; (?) unclear; (X) not applicable.

if the case manager was an administrative case manager (employed by an insurance company).

\section{Types of outcome measures}

Studies with one or more of the following outcome measures were included: readmission, duration of hospital readmissions, emergency department (ED) visits, functional status, quality of life, and patient satisfaction.

\section{Search strategy}

In order to identify relevant publications for the review, an extensive search was performed in MEDLINE (1966 until June 15, 2005) (Appendix A), and an analogous search was performed in EMBASE (1983 until June 15, 2005), the Cochrane Controlled Trials Register (the Cochrane Library Issue 2005), and Cinahl (1982 until June 15, 2005). The search was completed by checking the references of relevant publications (reviews and identified trials). The titles and abstracts of references identified by the search were screened independently by two reviewers (CL and DvdW) for their potential relevance and design. Since one of the reviewers was familiar with some of the studies beforehand, it was decided not to blind the studies during the selection procedure. The full version of an article was obtained if, from this initial assessment, it appeared to meet the inclusion criteria. The papers were screened for eligibility, checking first design then study population, intervention, and, finally, outcome measures. Any disagreements between the reviewers were resolved by discussion.

\section{Methodological quality assessment}

The methodological quality assessment and data extraction were carried out by two independent reviewers (CL and PdJ). The studies were not blinded for authors, institutions, or the journals in which they were published because the reviewers were both familiar with the literature on case management. The methodological quality of each study was assessed, using the Effective Practice and Organisation of Care quality assessment criteria [22] that were slightly adjusted for this systematic review. Assessment of methodological quality was piloted by using an RCT on disease management for heart failure [8], which was not included in the present review. Each study was scored with regard to concealment of allocation, baseline comparability, blinded assessment of primary outcomes, follow-up of patients or episode of care, follow-up of professionals, and protection against contamination. (Appendix B) Disagreements between the reviewers were resolved by discussion. Each item was scored as positive $(+)$, negative $(-)$, unclear (?), or not applicable (X). We used a cutoff point of 4 to identify studies of high methodological quality. 
Table 2

Characteristics of included studies

\begin{tabular}{lll}
\hline Authors & Methods & Participants \\
\hline Brand et al. [24] & CBA, 2 units sharing a single & 166 participants, \\
& medical ward. One ward & age $\geq 65$ years, previous \\
& assigned to intervention, other & admission last 6 months, \\
& ward to control condition & $\geq 2$ active comorbidities, \\
& & admitted with CHF
\end{tabular}

Laramee et al. [1]

RCT, first simple

randomization of patients, later blocks of 8 patients, enrolled

by clinical research coordinator

287 patients with either primary or secondary heart failure, all ages, having any comorbidity

Lob et al. [25]

McCorckle et al. [18] RCT, randomization of

Naylor et al. [2]

Rich et al. [19] patients, allocation using sealed opaque envelope technique

CBA, admission to intervention group by judgment of the case manager

$\mathrm{RCT}$, randomization of patients performed by a computer-generated algorithm

$\mathrm{RCT}$, randomization of patients, assigned on a 2:1 basis, stratified according to risk category
1507 patients with severe chronic illnesses and documented diagnosis of diabetes, history of frequent hospitalization, psychiatric problems, noncompliance or social problems

375 patients, age $\geq 60$ years, newly diagnosed with solid cancer, predicted survival $>6$ months, often comorbidities

363 patients with at least one somatic diagnosis at admission and poor postdischarge outcomes in an earlier study

98 patients, age $=70$ years, confirmed heart failure and classified as medium or high risk for early readmission

Interventions
I (83): screening for risk
factors, identification of
disease, medication,
self-management, social
issues, action plan,
coordination and liaison, referrals to allied health. Seen within 2 weeks, no home visits C (83): discharge planning and sometimes outpatient follow-up

I (141): early discharge planning, patient and family CHF education, promotion of optimal CHF medication. 12 weeks of telephone follow-up; Day 1 and 3 after discharge, Weeks 1, 2, 3, 4 , $6,8,10$, and 12

C (146): care as usual I (1050): co-coordinating care at home and coordinating medical appointments, facilitating care, e.g., ongoing support, telephone contact every 1 or 2 weeks. Duration: varied per patient C (457): ?

I (190): assessment and monitoring of physical, emotional, and functional status, teaching, counseling, and supporting. Providing direct care if needed, referral. Duration 4 weeks: 3 home visits and 5 telephone calls C (185): care as usual I (177): direct clinical care, education, coordination, referral, compliance increasing interventions, written letter at end of intervention. Duration: 4 weeks, at least 2 home visits, additional on needs, telephone availability 7 days/week, weekly telephone contact C (186): care as usual I(63): education about CHF, compliance improvement of medication, early discharge planning, emotional support. Home visits in first week: 3 times, subsequent visits, possibility for telephone contact C (35): care as usual
Authors conclusion

3 and 6 months follow-up. No significant difference found for readmission, ED visits, and quality of life

3 months follow-up. Outcomes significantly better in I for patient satisfaction; no significant difference for readmission rate and hospital days

12 months follow-up. Outcomes significantly better in I for readmission and total hospital days. No significant difference for ED visits.

6 months follow-up. Outcomes significantly worse in I for functional status

6 months follow-up. Outcomes significantly better in I for readmission. No significant difference for ED visits, functional status, and patient satisfaction

3 months follow-up. No significant difference for readmission, and hospital days 
Table 2 (continued)

\begin{tabular}{|c|c|c|c|c|}
\hline Authors & Methods & Participants & Interventions & Authors conclusion \\
\hline Rich et al. [3] & $\begin{array}{l}\text { RCT, randomization of patients } \\
\text { with the use of a } \\
\text { computer-generated list of } \\
\text { random numbers }\end{array}$ & $\begin{array}{l}282 \text { patients, age } \geq 70 \text { years, } \\
\text { confirmed heart failure and at } \\
\text { least one risk factor for early } \\
\text { readmission }\end{array}$ & $\begin{array}{l}\text { I (142): multidisciplinary } \\
\text { nurse-directed. Education, } \\
\text { compliance improvement of } \\
\text { medication and diet, } \\
\text { discharge planning, } \\
\text { identification of recurrent } \\
\text { problems. Home visits in } \\
\text { first week: } 3 \text { times, } \\
\text { subsequent visits, possibility } \\
\text { for telephone contact } \\
\text { C (140): care as usual }\end{array}$ & $\begin{array}{l}3 \text { months follow-up. } \\
\text { Outcomes significantly } \\
\text { better in I for readmission } \\
\text { and hospital days }\end{array}$ \\
\hline Sommers et al. [7] & $\begin{array}{l}\text { Cluster RCT, } 18 \text { doctors were } \\
\text { randomized using a random } \\
\text { number table to } \mathrm{C} \text { or I group }\end{array}$ & $\begin{array}{l}543 \text { patients, elderly (age } 65+ \\
\text { years), with at least } 2 \text { chronic } \\
\text { conditions and functional } \\
\text { deficits }\end{array}$ & $\begin{array}{l}\text { I (280): assessing health } \\
\text { care needs, formulating } \\
\text { treatment plan, monitoring, } \\
\text { coaching, promotion of } \\
\text { community-based services. } \\
\text { At least every } 6 \text { weeks } \\
\text { contact by telephone, home } \\
\text { visits or small group sessions } \\
\text { C (263) care as usual }\end{array}$ & $\begin{array}{l}18 \text { months follow-up. No } \\
\text { significant difference for } \\
\text { re-admission, ED visits, } \\
\text { and quality of life }\end{array}$ \\
\hline Weinberger et al. [9] & $\begin{array}{l}\text { Multicenter RCT, } \\
\text { randomization of patients, } \\
\text { stratified according to } \\
\text { entitlement status and index } \\
\text { disease. Assignment by } \\
\text { telephoning statistical } \\
\text { coordinator }\end{array}$ & $\begin{array}{l}1396 \text { patients with documented } \\
\text { diagnoses of DM, HF, or } \\
\text { COPD, extremely poor quality } \\
\text { of life scores at baseline }\end{array}$ & $\begin{array}{l}\text { I (695): assessment of } \\
\text { patients postdischarge } \\
\text { needs, education, } \\
\text { coordinating medical } \\
\text { appointments, monitoring } \\
\text { and updating treatment } \\
\text { plan. Telephone contact in } \\
2 \text { days after discharge, } \\
\text { discharge appointments. } \\
\mathrm{C}(701) \text { : care as usual }\end{array}$ & $\begin{array}{l}6 \text { months follow-up. } \\
\text { Outcomes significantly } \\
\text { better in I for patient } \\
\text { satisfaction. No significant } \\
\text { difference for proportion } \\
\text { of readmission over } 6 \text { month } \\
\text { and quality of life. Outcome } \\
\text { significantly worse in I for } \\
\text { days of hospitalization. }\end{array}$ \\
\hline Williams et al. [26] & $\begin{array}{l}\mathrm{RCT} \text {, randomization of } \\
\text { patients, using random } \\
\text { numbers table }\end{array}$ & $\begin{array}{l}75 \text { patients, admitted }>3 \text { times } \\
\text { within } 1 \text { year, chronic medical } \\
\text { illnesses }\end{array}$ & $\begin{array}{l}\text { I (35): } 9 \text { home visits, } \\
\text { obtaining vital signs, } \\
\text { cursory physical } \\
\text { assessment, patient and } \\
\text { family teaching. Duration } 3 \\
\text { months, } 9 \text { home visits } \\
\text { in total } \\
\text { C (40): no home nurse visits }\end{array}$ & $\begin{array}{l}5.5 \text { months follow-up. } \\
\text { Outcomes in favour of I } \\
\text { for readmission rate. }\end{array}$ \\
\hline
\end{tabular}

C, control group; CHF, chronic heart failure; COPD, chronic obstructive pulmonary disease; DM, diabetes mellitus; HF, heart failure; I, intervention group.

\section{Study characteristics}

The following data were extracted from the studies:

- characteristics of the study: design, conditions and group allocation;

- characteristics of the participants: number of participating patients, number of patients per group, somatic disease and other vulnerabilities;

- characteristics of the intervention: the type of intervention and the frequency and duration of the intervention;

- types of outcomes: readmission, duration of hospital readmissions, ED visits, functional status, quality of life, and patient satisfaction.

\section{Data analysis}

A qualitative analysis ("best-evidence synthesis") was first performed taking the methodological quality of the studies and the consistency of findings into account [23]. The studies were analysed and scored for each outcome separately. Studies were considered to be of relatively high methodological quality if at least four of the six quality criteria were met. Consistent findings were defined as statistically significant effects for a specific outcome in favour of case management in at least $75 \%$ of all studies.

The best-evidence synthesis resulted in the following levels of evidence:

Level 1 - strong evidence: generally consistent findings in multiple high-quality studies.

Level 2 -moderate evidence: generally consistent findings in multiple low-quality studies and/ or one high-quality study.

Level 3a -limited evidence: only one low-quality study.

Level $3 b$ - conflicting evidence: inconsistent findings in multiple studies.

Level 4 -no evidence from trials, no relevant studies identified [23]. 
The results concerning readmission rate were presented as relative risks (RRs) with corresponding 95\% confidence intervals $(95 \%$ CIs). For continuous outcomes (duration of hospitalization, ED visits, functional status, quality of life, and patient satisfaction), the mean difference (MD) and corresponding $95 \%$ CI were presented. A quantitative or meta-analysis was anticipated only if there was sufficient homogeneity across studies with regard to the study

Table 3

Outcomes on readmission, hospital days, ED visits, functional status, quality of life, and patient satisfaction

\begin{tabular}{|c|c|c|c|c|c|c|c|}
\hline \multicolumn{8}{|l|}{ Readmission } \\
\hline Authors & $\begin{array}{l}\text { Quality } \\
\text { score }\end{array}$ & $\begin{array}{l}\text { Length of } \\
\text { follow-up } \\
\text { (months) }\end{array}$ & $\begin{array}{l}\text { Patients: } \\
\text { N/follow-up (\%) }\end{array}$ & $\begin{array}{l}\text { Intervention } \\
\text { group: } N(\%)\end{array}$ & Control group: $N(\%)$ & $\mathrm{RR}(95 \% \mathrm{CI})$ & \\
\hline Brand et al. [24] & 3 & 3 & $186 / 154(93)$ & $30(36.1)$ & $30(36.1)$ & $0.97(0.66-1.45)$ & \\
\hline Laramee et al. [1] & 3 & 3 & $287 / 256(89)$ & 49 (37) & $46(37)$ & $1.0(0.74-1.40)$ & \\
\hline Lob et al. [25] & 2 & 12 & $1507 / 782(52)$ & $\begin{array}{l}\text { Mean change (S.D.), } \\
-0.71(2.16)\end{array}$ & $\begin{array}{l}\text { Mean change (S.D.), } \\
-0.18(2.54)\end{array}$ & $\begin{array}{l}\operatorname{MD}(95 \% \mathrm{CI}) \\
-0.53(-0.89--0.17)\end{array}$ & \\
\hline Naylor et al. [2] & 5 & 6 & $363(100)$ & $36(20.1)$ & $69(37.1)$ & $0.55(0.39-0.78)$ & \\
\hline Rich et al. [19] & 4 & 3 & $98(100)$ & $21(33.3)$ & $16(45.7)$ & $0.73(0.44-1.2)$ & \\
\hline Rich et al. [3] & 5 & 3 & $282(100)$ & $41(28.9)$ & $59(42.1)$ & $0.69(0.5-0.95)$ & \\
\hline Sommers et al. [7] & 5 & 18 & $543 / 465(86.6)$ & Insufficient data & Insufficient data & OR $0.26(0.08-0.84)^{\mathrm{a}}$ & \\
\hline Weinberger et al. [9] & 5 & 6 & $1396(100)$ & $340(49)$ & 308 (44) & $1.11(0.99-1.25)$ & \\
\hline Williams et al. [26] & 2 & 5.5 & Insufficient data & Insufficient data & Insufficient data & Insufficient data & \\
\hline \multicolumn{8}{|l|}{ Hospital days } \\
\hline Authors & $\begin{array}{l}\text { Quality } \\
\text { score }\end{array}$ & $\begin{array}{l}\text { Length of } \\
\text { follow-up } \\
\text { (months) }\end{array}$ & $\begin{array}{l}\text { Patients: } \\
N / \text { follow-up }(\%)\end{array}$ & $\begin{array}{l}\text { Intervention group: } \\
\text { mean (S.D.) }\end{array}$ & $\begin{array}{l}\text { Control group: } \\
\text { mean (S.D.) }\end{array}$ & MD $(95 \% \mathrm{CI})$ & \\
\hline Laramee et al. [1] & 3 & 3 & $287 / 256(89)$ & $6.9(6.5)$ & $9.5(9.8)$ & $-2.60(-4.65$ to -0.55$)$ & \\
\hline Lob et al. [25] & 2 & 12 & $1507 / 782(52)$ & $\begin{array}{l}\text { Mean change (S.D.), } \\
-5.8(20.6)\end{array}$ & $\begin{array}{l}\text { Mean change (S.D.), } \\
-0.8(15.7)\end{array}$ & $-5.00(-7.62$ to -2.38$)$ & \\
\hline Naylor et al. [2] & 5 & 6 & $363(100)$ & $1.53(3.69)$ & $4.09(8.53)$ & $-2.56(-3.88$ to -1.24$)$ & \\
\hline Rich et al. [19] & 4 & 3 & $98(100)$ & $4.3(8.7)$ & $5.7(11.8)$ & $-1.40(-5.86$ to 3.06$)$ & \\
\hline Rich et al. [3] & 5 & 3 & $282(100)$ & $3.9(10.0)$ & $6.2(11.4)$ & $-2.30(-4.47$ to -0.13$)$ & \\
\hline Weinberger et al. [9] & 5 & 6 & $1396(100)$ & $10.2(19.8)$ & $8.8(19.7)$ & $1.40(-0.67$ to 3.47$)$ & \\
\hline \multicolumn{8}{|l|}{ ED visits } \\
\hline Authors & $\begin{array}{l}\text { Quality } \\
\text { score }\end{array}$ & $\begin{array}{l}\text { Length of } \\
\text { follow-up } \\
\text { (months) }\end{array}$ & $\begin{array}{l}\text { Patients: } \\
N / \text { follow-up }(\%)\end{array}$ & $\begin{array}{l}\text { Intervention } \\
\text { group: } N(\%)\end{array}$ & Control group: $N(\%)$ & $\mathrm{RR}(95 \% \mathrm{CI})$ & \\
\hline Brand et al. [24] & 3 & 6 & $186 / 154(93)$ & $18(21.7)$ & $15(18.1)$ & $\begin{array}{l}\text { RR }(95 \% \text { CI }) \\
1.17(0.64-2.15)\end{array}$ & \\
\hline Lob et al. [25] & 2 & 12 & $1507 / 782(52)$ & $\begin{array}{l}\text { Mean change (S.D.), } \\
-0.20(4.14)\end{array}$ & $\begin{array}{l}\text { Mean change (S.D.), } \\
-0.14(3.11)\end{array}$ & $\begin{array}{l}\operatorname{MD}(95 \% \mathrm{CI}) \\
-0.06(-0.58 \text { to } 0.46)\end{array}$ & \\
\hline Naylor et al. [2] & 5 & 6 & $363(100)$ & Mean (S.D.) 0.1 (0.5) & Mean (S.D.) $0.2(0.4)$ & $P .21^{\mathrm{b}}$ & \\
\hline Sommers et al. [7] & 5 & 18 & $543 / 465(85.6)$ & Insufficient data & Insufficient data & $P .77^{\mathrm{c}}$ & \\
\hline \multicolumn{8}{|l|}{ Functional status } \\
\hline First author: & $\begin{array}{l}\text { Quality } \\
\text { score }\end{array}$ & $\begin{array}{l}\text { Length of } \\
\text { follow-up } \\
\text { (months) }\end{array}$ & $\begin{array}{l}\text { Patients: } \\
N / \text { follow-up (\%) }\end{array}$ & Scale & $\begin{array}{l}\text { Intervention, } \\
\text { mean (S.D.) }\end{array}$ & Control, mean (S.D.) & $\operatorname{MD}(95 \% \mathrm{CI})$ \\
\hline McCorckle et al. [18] & 3 & 6 & $375 / 305(81.3)$ & $\begin{array}{l}\text { Enforced Social } \\
\text { Dependency Scale }\end{array}$ & $18.85(8.0)$ & $16.94(6.9)$ & $1.91(0.24-3.58)$ \\
\hline Naylor et al. [2] & 4 & 6 & Insufficient data & $\begin{array}{l}\text { Enforced Social } \\
\text { Dependency Scale }\end{array}$ & Insufficient data & Insufficient data & n.s. \\
\hline \multicolumn{8}{|l|}{ Quality of life } \\
\hline Brand et al. [24] & 1 & 3 & $186 / 118(71.1)$ & $\begin{array}{l}\text { Assessment of } \\
\text { QoL Instrument }\end{array}$ & Insufficient data & Insufficient data & $\begin{array}{l}?(-23.5 \% \\
\text { to }-2.4 \%)\end{array}$ \\
\hline Rich et al. [3] & 3 & 3 & $282 / 126(44.6)$ & $\begin{array}{l}\text { Chronic Heart Failure } \\
\text { Questionnaire }\end{array}$ & $\begin{array}{l}\text { Mean change (S.D.), } \\
22.1(20.8)\end{array}$ & $\begin{array}{l}\text { Mean change (S.D.), } \\
11.3(16.4)\end{array}$ & $10.8(4.29-17.31)$ \\
\hline Sommers et al. [7] & 3 & 18 & $543 / 384(70.7)$ & SF-36 & Insufficient data & Insufficient data & $P=.8$ \\
\hline Weinberger et al. [9] & 5 & 6 & 1396/1187 (85) & SF-36 & Insufficient data & Insufficient data & n.s. \\
\hline
\end{tabular}


Table 3 (continued)

Patient satisfaction

\begin{tabular}{|c|c|c|c|c|c|c|c|}
\hline First author: & $\begin{array}{l}\text { Quality } \\
\text { score }\end{array}$ & $\begin{array}{l}\text { Length of } \\
\text { follow-up } \\
\text { (months) }\end{array}$ & $\begin{array}{l}\text { Patients: } \\
\text { N/follow-up (\%) }\end{array}$ & Scale & $\begin{array}{l}\text { Intervention, } \\
\text { mean (S.D.) }\end{array}$ & Control, mean (S.D.) & MD $(95 \% \mathrm{CI})$ \\
\hline Laramee et al. [1] & 2 & 3 & $287 / 251(87.5)$ & Participant survey & Insufficient data & Insufficient data & $P=.01(13 / 16$ items $)$ \\
\hline Naylor et al. [2] & 4 & 6 & Insufficient data & Investigator developed & Insufficient data & Insufficient data & n.s. \\
\hline Weinberger et al. [9] & 5 & 6 & $1396 / 1187(85)$ & $\begin{array}{l}\text { Patient Satisfaction } \\
\text { Questionnaire }\end{array}$ & Insufficient data & Insufficient data & $P=.001$ \\
\hline
\end{tabular}

Readmission: McCorckle et al. [18], not assessed.

Hospital days: Sommers et al. [7], McCorckle et al. [18], and Williams et al. [26], not assessed.

ED visits: Weinberger et al. [9], Rich et al. [3,19], Laramee et al. [1], McCorckle et al. [18], and Williams et al. [26], not assessed.

Functional status: Weinberger et al. [6], Rich et al. [3,19], Sommers et al. [7], Laramee et al. [1], Lob et al. [25], and Williams et al. [26], not assessed.

Quality of life: Naylor et al. [2], Rich et al. [19], Laramee et al. [1], McCorckle et al. [18], Lob et al. [25], and Williams et al. [26], not assessed.

Patient satisfaction: Rich et al. [3,19], Sommers et al. [7], McCorckle et al. [18], Lob et al. [25], and Williams et al. [26], not assessed.

n.s. $=$ not significant.

a Adjusted OR and longitudinal data analysis.

${ }^{b}$ Number of patients unclear.

c Adjusted and longitudinal data analysis.

population (type and severity of disease), intervention (content of case management), and outcome assessment (type of outcome measure and length of follow-up).

\section{Results}

\section{Literature search and study selection}

We first performed our search in MEDLINE ( 928 titles of articles), then in EMBASE (195 additional hits), and subsequently in the Cochrane Library (79 additional hits) and Cinahl (416 additional hits). By reference checking, we identified an additional 20 hits, resulting in a total of 1638 hits. (Fig. 1) Based on titles and abstracts, 105 full-text articles were retrieved, 10 of which met the inclusion criteria $[1-3,7,9,18,19,24-26]$.

Of the 95 studies that were excluded, 26 were not an $\mathrm{RCT}$, a CCT, a CBA, or a time series design; the patient population of 53 studies was not considered to be complex or the patient complexity was not described explicitly; in 15 studies the intervention did not concern case management; and one study did not use any of the selected outcome measures.

\section{Methodological quality of the included studies}

Studies were ranked in alphabetical order (Table 1). Concealment of allocation was scored positively in 7 out of 10 studies, but baseline comparability was often insufficiently described or negatively evaluated (6/10). The blinded assessment of outcomes and the follow-up of patients were scored for each outcome measure separately. In general, for the more objective, care-related outcome measures (readmissions, duration of hospital readmissions, ED visits) the follow-up of patients was mostly evaluated positively (15/19). For patient-oriented outcome measures (quality of life, functional status, and patient satisfaction), more than half of the outcome measurements were evaluated negatively (5/9) with loss to follow-up ranging between $12 \%$ and $55 \%$. The followup of professionals was only described in one study. All except one of the studies had positive scores for protection against contamination $(9 / 10)$.

\section{Study characteristics}

The study characteristics are summarized in Table 2 .

Eight of the studies were RCTs $[1-3,7,9,18,19,26]$ and two were CBA studies $[24,25]$. The number of participating patients (median, 325; minimum, 75; maximum, 1507) and the duration of the follow-up (median, 6 months; minimum, 3 months; maximum, 18 months) varied considerably. Some of the populations consisted of frail elderly people $[3,7,18,19,24]$ others were patients with both somatic diseases and mental health problems $[1,25,26]$, and some were patients with a high risk of readmission [2,9]. Case management consisted of assessment of the client's needs, development of a comprehensive service plan, arrangement of service delivery, monitoring and assessment of services, evaluation, and follow-up, but frequency and duration of home visits varied considerably. There was a wide variation in outcome measures. Although readmission was used as an outcome measure in nine studies [1-3,7,9,19,24-26], there was a difference in the definition: only first readmission (with variable length of follow-up) or any readmission in the first 60 days after discharge. The number of ED visits was measured in four studies $[2,7,24,25]$. Quality of life or functional status was measured in six studies $[2,3,7,9,18,24]$, but different scales were used or insufficient data were presented to enable the calculation of mean differences. 


\section{Effectiveness of case management}

Given the heterogeneity across studies with regard to study population and outcome assessment, we decided against statistical pooling of the results. The best-evidence synthesis resulted in the following conclusions (Table 3).

\section{Readmission}

There is conflicting evidence that case management has a positive effect on the number of readmissions.

Nine studies measured readmission [1-3,7,9,19,24-26]. Three studies $[2,3,7]$, all of relatively high quality and one study of low quality [25], reported a positive result in favour of the intervention group. However, four studies $[1,9,19,24]$ two which were of high quality $[9,19]$, could not demonstrate significantly better outcomes for case management. One study presented insufficient data [26], so no conclusion could be drawn.

\section{Hospital days}

There is conflicting evidence that case management has a positive effect on the duration of hospital readmissions.

Six studies measured duration of hospitalization [1-3, $9,19,25]$. Four studies were of relatively high quality $[2,3,9,19]$; two showed a positive result in favour of the intervention group $[2,3]$, but the other two $[9,19]$ showed no significant differences compared to the control group. The two studies with low-quality scores reported positive effects of case management on the duration of hospitalization $[1,25]$.

\section{ED visits}

There is strong evidence that case management has no significant effect on the number of ED visits.

Of the four studies that measured the number of ED visits, two were of high quality [2,7] and two were of low quality [24,25]. None of these studies reported a positive effect on the number of ED visits.

\section{Functional status}

There is no evidence that case management has a positive effect on the functional status of patients.

Only two studies measured functional status [2,18]. One study, which was of high quality, presented insufficient data [2] but did not find significant difference between intervention and control group. The other study, which was of low quality [18], also found no significant difference.

\section{Quality of life}

There is conflicting evidence that case management has a positive effect on quality of life.

Four studies measured quality of life $[3,7,9,24]$. Three of these studies presented insufficient data $[7,9,24]$. One was of high [9] and two were of low quality [7,24], but none found any difference between the intervention and the control group. The fourth study [3] reported a significant difference in favour of the intervention group, but this study was considered to be of low quality.

\section{Patient satisfaction}

There is moderate evidence that case management has a positive effect on patient satisfaction.

Three studies measured patient satisfaction [1,2,9], but none of these studies presented sufficient data. Two studies, one of high quality [9] and one of low quality [1], reported a positive result in favour of case management. The other study [2], which was of high quality, found no significant difference between the intervention and the control group.

\section{Discussion}

In this systematic review, we summarized the available literature on the effectiveness of a postdischarge nurse-led case management for complex patients in general health care. The review provides moderate evidence that case management has a positive effect on patient satisfaction. There is strong evidence that case management has no significant effect on the number of ED visits.

However, given the conflicting results on the other outcome variables it was not possible to draw firm conclusions with regard to the effectiveness of case management on other relevant outcomes.

\section{Search strategy}

We cannot rule out the possibility of publication bias since our review was limited to published research. This may have resulted in an overestimation of treatment effect [27], as the addition of nonjournal publications has been shown to influence effect estimates toward a null result [28,29]. A search for unpublished studies was unfortunately beyond the scope of this review. Our review did not provide strong evidence in favour of case management and contains studies with both positive and negative findings. Given the small number of studies, a funnel plot could not provide sufficient evidence to suspect or rule out publication bias. We consider it unlikely that our conclusions would have been greatly affected if we had included unpublished studies.

\section{Quality assessment}

The use of a cutoff score of four positively evaluated items to identify studies of high quality is arbitrary. However, sensitivity analyses indicate that a cutoff score of three or five items would not have modified our conclusions to a great extent (data not shown). It is noteworthy that for the patient-oriented outcome variables (functional status, quality of life, and patient satisfaction) the follow-up rates reported in most studies were low (less than $80 \%$ ). However, in such patients with complex somatic and psychosocial problems, high follow-up rates are often difficult to achieve and require much time and effort. 


\section{Heterogeneity}

Several systematic reviews have been performed evaluating the effectiveness of case management for specific populations with a positive effect on the number of readmission [30,31] or improvement of glycemic control [32]. One may consider all chronically ill patients (such as patients with diabetes, heart failure, or chronic obstructive pulmonary disease to be complex, but in practice, complex patients constitute a small subgroup [32] [i.e., patients with acute or chronic medical condition(s) and described other vulnerabilities, such as (psychiatric) comorbidity, frail elderly people, patients with social problems, reduced functional status, or poor quality of life]. The characteristics of complex patients varied greatly across the studies, and this also applied to the content of the interventions and the duration of follow-up. The heterogeneity in populations, interventions, and outcomes found in this study is inherent to the objective of this review. Research that has recently become available describes patients in their levels of complexity related to their health risks and health-related needs $[33,34]$, but such a systematic assessment of complexity has not yet been widely implemented.

It is important to take not only statistical significance into account, but also to consider the clinical relevance of the reported results. The studies included in our review reported widely ranging results with regard to the clinical effects of case management. The reported mean difference in duration of hospitalization, for example, ranged between 1 and 5 days over a period of 3 to 12 months, compared to usual care. Such differences in clinical effects may outweigh the additional costs of employing a case manager. As far as we know, no economic evaluation of case management has yet been performed among complex patients in ambulatory care. The case manager is an extra expense, but if this results in less readmission or enables patients to live longer independently at home with a better quality of life, it could provide strong arguments for the development of case management programs. Readmission rate is a frequently used outcome measure in studies investigating the effectiveness of case management. It should be noted, however, that (re)admission sometimes can be very beneficial for patients suffering from complicated medical illnesses causing diagnostic dilemmas. This does not always indicate a poor outcome.

We have to look for methods to organise our health care in such a way that we can provide adequate care for the increasing number of complex patients. At this point, we know that chronic disease management programs can be effective $[4,35,36]$, but for case management, we do not have evidence that they are. Although patients report to be satisfied about case management, there is no proof that this is an effective way to organise our care. One of the main difficulties in research in this field is the lack of clear definitions and criteria for case complexity.

There is need for high-quality RCTs that include clearly defined measures of complexity or frailty that make it possible to select more homogeneous populations, which are based on focused and well-defined interventions and long-term outcome assessment, and have sufficient statistical power to detect clinically important differences. Most of the studies included were conducted in a US health maintenance organization setting. The organisation and function of primary care and other health care systems are different. Therefore, further research on other health care systems is recommended. In chronic disease management programs, complex patients should be detected so that in future studies these complex patients can be counseled by case managers, not only to evaluate important patient outcomes such as readmission and quality of life, but also to evaluate the cost effectiveness of case management in these patient groups.

\section{References}

[1] Laramee AS, Levinsky SK, Sargent J, Ross R, Callas P. Case management in a heterogeneous congestive heart failure population: a randomized controlled trial. Arch Intern Med 2003;163:809-17.

[2] Naylor MD, Brooten D, Campbell R, Jacobsen BS, Mezey MD, Pauly MV, et al. Comprehensive discharge planning and home follow-up of hospitalized elders: a randomized clinical trial. JAMA 1999;281:613-20.

[3] Rich MW, Beckham V, Wittenberg C, Leven CL, Freedland KE, Carney RM. A multidisciplinary intervention to prevent the readmission of elderly patients with congestive heart failure. N Engl J Med 1995;333:1190-5.

[4] Weingarten SR, Henning JM, Badamgarav E, Knight K, Hasselblad V, Gano A, et al. Interventions used in disease management programmes for patients with chronic illness — which ones work? Meta-analysis of published reports. Br Med J 2002;325:925.

[5] Institute for Clinical System Integration. Technology assessment: care management for chronic illness, the frail elderly, and acute myocardial infarction. Bloomington (MN): Institute for Clinical System Integration (ICSI), 1998.

[6] Holloway F, McLean EK, Robertson JA. Case management. Br J Psychiatry 1991;159:142-8.

[7] Sommers LS, Marton KI, Barbaccia JC, Randolph J. Physician, nurse, and social worker collaboration in primary care for chronically ill seniors. Arch Intern Med 2000;160:1825-33.

[8] Stewart S, Marley JE, Horowitz JD. Effects of a multidisciplinary, home-based intervention on unplanned readmissions and survival among patients with chronic congestive heart failure: a randomised controlled study. Lancet 1999;354:1077-83.

[9] Weinberger M, Oddone EZ, Henderson WG. Does increased access to primary care reduce hospital readmissions? Veterans Affairs Cooperative Study Group on Primary Care and Hospital Readmission. N Engl J Med 1996;334:1441-7.

[10] West JA, Miller NH, Parker KM, Senneca D, Ghandour G, Clark M, et al. A comprehensive management system for heart failure improves clinical outcomes and reduces medical resource utilization. Am J Cardiol 1997;79:58-63.

[11] Lyketsos CG, Levenson J, APM Task Force. Proposal for recognition of" "psychiatry of the medically ill" as a psychiatric subspecialty. 2001. Ref Type: Generic.

[12] Gilmer TP, O'Connor PJ, Rush WA, Crain AL, Whitebird RR, Hanson AM, et al. Predictors of health care costs in adults with diabetes. Diabetes Care 2005;28:59-64.

[13] Ludman EJ, Katon W, Russo J, Von KM, Simon G, Ciechanowski P, et al. Depression and diabetes symptom burden. Gen Hosp Psychiatry 2004;26:430-6. 
[14] Lustman PJ, Anderson RJ, Freedland KE, de GM, Carney RM, Clouse RE. Depression and poor glycemic control: a meta-analytic review of the literature. Diabetes Care 2000;23:934-42.

[15] Fink P. Mental illness and admission to general hospitals: a register investigation. Acta Psychiatr Scand 1990;82:458-62.

[16] Saravay SM, Lavin M. Psychiatric comorbidity and length of stay in the general hospital A critical review of outcome studies. Psychosomatics 1994;35:233-52.

[17] Saravay SM, Pollack S, Steinberg MD, Weinschel B, Habert M. Fouryear follow-up of the influence of psychological comorbidity on medical rehospitalization. Am J Psychiatry 1996;153:397-403.

[18] McCorkle R, Strumpf NE, Nuamah IF, Adler DC, Cooley ME, Jepson $\mathrm{C}$, et al. A specialized home care intervention improves survival among older post-surgical cancer patients. J Am Geriatr Soc 2000;48:1707-13.

[19] Rich MW, Vinson JM, Sperry JC, Shah AS, Spinner LR, Chung MK, et al. Prevention of readmission in elderly patients with congestive heart failure: results of a prospective, randomized pilot study. J Gen Intern Med 1993;8:585-90.

[20] Plsek PE, Greenhalgh T. Complexity science: the challenge of complexity in health care. BMJ 2001;323:625-8.

[21] Wilson T, Holt T, Greenhalgh T. Complexity science: complexity and clinical care. Br Med J 2001;323:685-8.

[22] The Cochrane Effective Practice and Organisation of Care Group (EPOC). Data collection checklist. University of Ottawa, July 2002. Available at: www.epoc.uottawa.ca/tools.htm.

[23] Van Tudler MW, Furlan A, Bombardier C, Bouter L. Updated method guidelines for systematic reviews in the Cochrane collaboration back review group. Spine 2003;28:1290-9.

[24] Brand CA, Jones CT, Lowe AJ, Nielsen DA, Roberts CA, King BL, et al. A transitional care service for elderly chronic disease patients at risk of readmission. Aust Health Rev 2004;28:275-84.

[25] Lob SH, Kohatsu ND. Case management: a controlled evaluation of persons with diabetes. Clin Perform Qual Health Care 2000; $8: 105-11$

[26] Williams H, Blue B, Langlois PF. Do follow-up home visits by military nurses of chronically ill medical patients reduce readmissions? Mil Med 1994;159:141-4.

[27] Schulz KF, Chalmers I, Hayes RJ, Altman DG. Empirical evidence of bias Dimensions of methodological quality associated with estimates of treatment effects in controlled trials. JAMA 1995;273:408-12.

[28] Burdett S, Stewart LA, Tierney JF. Publication bias and metaanalyses: a practical example. Int $\mathrm{J}$ Technol Assess Health Care 2003;19:129-34.

[29] Easterbrook PJ, Berlin JA, Gopalan R, Matthews DR. Publication bias in clinical research. Lancet 1991;337:867-72.

[30] Philbin EF. Comprehensive multidisciplinary programs for the management of patients with congestive heart failure. J Gen Intern Med 1999;14:130-5.

[31] Phillips CO, Wright SM, Kern DE, Singa RM, Shepperd S, Rubin HR. Comprehensive discharge planning with postdischarge support for older patients with congestive heart failure: a meta-analysis. JAMA 2004;291:1358-67.

[32] Norris SL, Nichols PJ, Caspersen CJ, Glasgow RE, Engelgau MM, Jack L, et al. The effectiveness of disease and case management for people with diabetes A systematic review. Am J Prev Med 2002;22(4 Suppl): $15-38$.

[33] de Jonge P, Huyse FJ, Slaets JP, Sollner W, Stiefel FC. Operationalization of biopsychosocial case complexity in general health care: the INTERMED project. Aust N Z J Psychiatry 2005;39:795-9.

[34] Huyse FJ, Lyons JS, Stiefel F, Slaets J, de JP, Latour C. Operationalizing the biopsychosocial model: the Intermed. Psychosomatics 2001;42:5-13.

[35] Lavery LA, Wunderlich RP, Tredwell JL. Disease management for the diabetic foot: effectiveness of a diabetic foot prevention program to reduce amputations and hospitalizations. Diabetes Res Clin Pract 2005;70:31-7.
[36] Roccaforte R, Demers C, Baldassarre F, Teo KK, Yusuf S. Effectiveness of comprehensive disease management programmes in improving clinical outcomes in heart failure patients A meta-analysis. Eur J Heart Fail 2005;7:1133-44.

\section{Appendix A. Complete search strategy PUBMED 1966 till June 15, 2005}

\#1

("Nurses"[MeSH] OR nurse[tw] OR nurses[tw]) AND ("Patient Care Management"[MESH] OR "Disease Management"[MESH] OR "Case Management"[MESH] OR Patient Care Team[mesh] OR ((multidisciplin*[ti] OR interdisciplin*[ti]) AND (care[ti] OR management[ti] OR managing[ti])) OR aftercare[tw] OR "case management"[tw] OR "patient care management"[tw] OR "disease management"[tw] OR "continuity of patient care"[mesh] OR (nurse[ti] AND (led[ti] OR directed[ti]))) AND (copd[tw] OR obstructive pulmonary disease[tw] OR obstructive lung disease[tw] OR "Pulmonary Disease, Chronic Obstructive"[MeSH] OR "bronchial diseases" [mesh] OR asthma[tw] OR asthmatic[tw] OR rheuma[tw] OR rheumatic[tw] OR rheumatoid[tw] OR "arthritis, rheumatoid" [mesh] OR diabetes[tw] OR diabetes mellitus [mesh] OR diabetic[tw] OR "coronary disease"[mesh] OR heart failure[tw] OR "heart failure, congestive"[mesh] OR ((kidney[tw] OR renal[tw]) AND (insufficient[tw] OR insufficiency[tw] OR failure[tw])) OR "kidney failure" [mesh] OR ((chronic[tw] OR chronically[tw]) AND (ill[tw] OR illness[tw] OR illnesses[tw] OR disease[tw] OR diseases[tw] OR diseased[tw])))

\#2

("Home Care Agencies"[MeSH] OR "Home Care Services"[MeSH] OR "House Calls"[MeSH] OR ambulatory[tw] OR outpatient[tw] OR outpatients[tw] OR home[ti] OR "home visit"[tw] OR "home visits"[tw] OR "Ambulatory Care Facilities"[MeSH] OR "Ambulatory Care"[MeSH] OR "Outpatient Clinics, Hospital"[MeSH] OR "Outpatients" [MeSH] OR (after[tw] AND discharge[tw]))

\section{\#3}

("Evaluation Studies"[MeSH] OR "Nursing Evaluation Research"[MeSH] OR "Health Care Evaluation Mechanisms"[MeSH] OR "Program Evaluation"[MeSH] OR "Outcome Assessment (Health Care)"[MeSH] OR "Treatment Outcome"[MeSH] OR "Outcome and Process Assessment (Health Care)"[MeSH] OR "Health Services Research" [MeSH] OR Comparative study[mesh] OR random[tw] $\mathrm{OR}$ randomised[tw] OR randomisation[tw] OR randomization[tw] OR clinical trial[pt] OR longitudinal studies [mesh]) AND ("Costs and Cost Analysis"[MeSH] OR Hospitalization[mesh] OR "Quality-Adjusted Life Years" [MeSH] OR Patient satisfaction[mesh] OR Health promotion[mesh] OR outcome[tw] OR outcomes[tw] OR cost[tw] OR costs[tw] OR qol[tw] OR "quality of life"[tw] OR mortality[tw] OR comorbidity[tw] OR comorbidity[tw] OR 
admission[tw] OR readmission[tw] OR readmission[tw] OR survival[tw])

\#1 AND (\#2 OR \#3) NOT case reports[pt] NOT (child[mesh] NOT adult[mesh])

\section{Appendix B. Explanation of the criteria from Table 1}

Quality criteria for RCTs, CCTs, and CBA:

Concealment of allocation (protection against selection bias): positive if the unit of allocation was by patient or episode of care and there was some form of centralised randomization scheme, an on-site computer system or sealed opaque envelopes were used. Or, for CBA: positive if characteristics of study and control providers are reported and similar.
Baseline measurements: positive if patient outcomes were measured prior to the intervention and no substantial differences were presented across study groups.

Blinded assessment of primary outcome(s) (protection against detection bias): positive if the authors state explicitly that the primary outcome variables were assessed blindly or the outcome variables are objective.

Follow-up of patients or episode of care (protection against exclusion bias): positive if outcome measures obtained for $80 \%$ to $100 \%$ of patients who are randomized or for patients who entered the trial, and if there is an objective data collection system.

Follow-up of professionals (protection against exclusion bias): positive if outcome measures obtained for $80 \%$ to $100 \%$ of health care professionals are randomized.

Protection against contamination: positive if allocation was by community, institution, or practice, and it is unlikely that the control received the intervention. 